\title{
Construção de metodologia de capacitação em alimentação e nutrição para educadores
}

\author{
Construction of a methodology to train \\ educators in food and nutrition
}

\author{
Renata BERNARDON ${ }^{1}$ \\ Juliana Rezende Melo da SILVA' \\ Gabriela Tavares CARDOSO' \\ Renata Alves MONTEIRO \\ Nina Flávia de Almeida AMORIM ${ }^{1}$ \\ Bethsáida de Abreu Soares SCHMITZ1 \\ Maria de Lourdes Carlos Ferreirinha RODRIGUES'
}

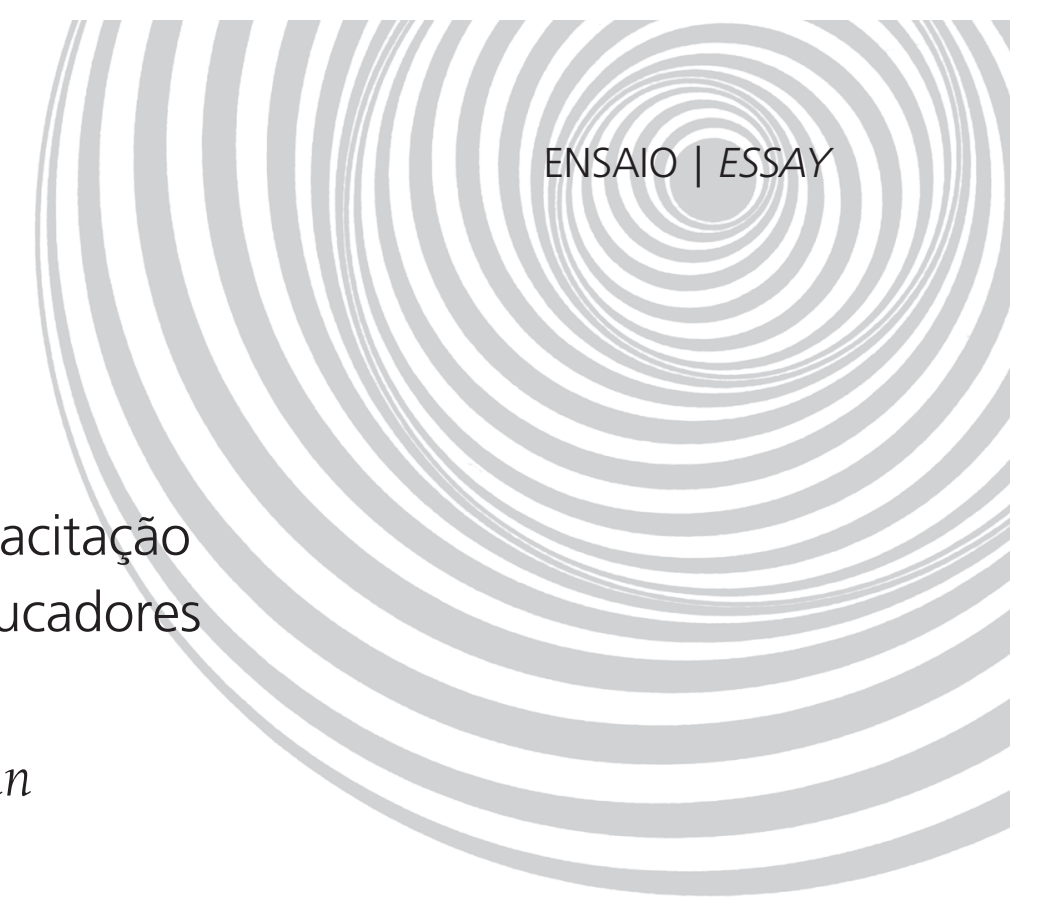

RES U M O

Neste artigo apresenta-se a construção de uma metodologia de capacitação em educação nutricional para educadores de ensino infantil e fundamental até a $4^{\mathrm{a}}$ série. O desenvolvimento desta metodologia foi feito em quatro escolas de diferentes realidades socioeconômicas do Distrito Federal, Brasil, tendo sido convidados todos os 59 educadores das mesmas. A metodologia foi construída incluindo quatro fases: demanda, pré-análise, foco e enquadre e planejamento flexível. Esta proposta insere-se em uma perspectiva de educação permanente baseada no construtivismo. Dos 59 educadores, $81 \%(n=48)$ participaram da etapa de demanda que identificou dificuldades, expectativas e principais temas para o curso. Os temas geradores verificados na etapa pré-análise foram: alimentação saudável; opções de refeições saudáveis; estratégias para a promoção de hábitos alimentares saudáveis com a comunidade; contexto da alimentação na atualidade; aspectos legais sobre alimentação na escola e aproveitamento total de alimentos. O foco do planejamento foi definido como "Alimentação saudável na escola" e o enquadre como um curso de 60 horas a ser realizado na Universidade de Brasília e nas escolas participantes. No planejamento flexível definiram-se os objetivos gerais e específicos do curso, as competências esperadas para os educadores após o curso e toda a programação com seus respectivos planos de aula. Esta proposta representa uma opção norteadora para ações de educação nutricional com este público, de forma a contribuir para a modificação do perfil epidemiológico atual dos escolares.

Termos de indexação: Alimentação escolar. Capacitação. Educação alimentar e nutricional.

\section{A B S T R A C T}

This article presents the construction of a methodology to train preschool and first- to fourth-grade teachers in food and nutrition. The methodology was developed in four schools with different socioeconomic profiles

\footnotetext{
${ }^{1}$ Universidade de Brasília, Faculdade de Ciências da Saúde, Observatório de Políticas de Segurança Alimentar e Nutrição. Campus Universitário Darcy Ribeiro, Sala AC 110, 70910-900, Brasília, DF, Brasil. Correspondência para/Correspondence to: M.L.C.F. RODRIGUES. E-mail:<mloufer@terra.com.br>.
} 
390 | R. BERNARDON et al.

in the Federal District, Brazil, of which all of the 59 teachers were invited. The methodology was constructed in four phases: demand, pre-analysis, focus/applicability and flexible planning and aims to provide permanent nutrition education in a constructivistic way. Of the 59 educators, $81 \%(n=48)$ participated in the demand phase, where difficulties and expectations were identified and the main subjects for the course were determined. The generating subjects verified in the pre-analysis phase were: healthy eating; healthy meal options; strategies to promote healthy eating habits in the community; current context of nutrition; legal aspects of food and nutrition at school and letting nothing go to waste. The focus of planning was "Healthy eating in the school environment". A 60-hour course would then be given at the University of Brasilia and at the participating schools. The flexible planning phase established the general and specific goals of the course, the skills to be acquired by the teachers during the course and the course program with the respective class plans. This methodology proposes a way to provide nutrition education to this public and therefore contribute to change the current epidemiological data of the students.

Indexing terms: Eating at school. Training. Food and nutrition education.

\section{N T R O D U ÇÃ O}

No Brasil, o consumo de alimentos de grande densidade energética, com altos teores de açúcar e gorduras, ou excessivamente ricos em sódio tem se ampliado. Conseqüentemente, as doenças crônicas não transmissíveis (DCNT), como o diabetes mellitus e as doenças cardiovasculares, são cada vez mais comuns, inclusive em crianças. As DCNT associadas às elevadas prevalências de excesso de peso entre crianças e adolescentes, representam graves repercussões para a saúde atual e futura dos mesmos ${ }^{1-4}$. Verifica-se a necessidade de redução das complicações associadas à alimentação e nutrição inadequadas, sendo que ações desta natureza devem estar relacionadas com a promoção de modos de vida saudáveis 5 .

Para tanto, é necessário sensibilizar a população de forma a possibilitar estratégias concretas que favoreçam a adoção e a manutenção desses novos estilos de vida. Verifica-se, portanto, a importância do olhar atento para o espaço da escola, com todo seu rol de possibilidades de interações e mudanças em termos de comportamento ${ }^{6}$.

A promoção da saúde na escola se caracteriza pela atuação concomitante de três grandes áreas: ambiente saudável, participação dos serviços de saúde e educação em saúde ${ }^{7-8}$. Esta última área consiste em um conjunto de estratégias sistematizadas para impulsionar a cultura e valorizar a alimentação ${ }^{8-9}$. Nesse sentido, a escola é um ambiente propício para a implantação de projetos dessa natureza, visto ser um espaço importante para a concretização de iniciativas de promoção da saúde, incentivando o desenvolvimento saudável e as relações construtivas e harmônicas, contribuindo para a formação de cidadãos $\operatorname{críticos}^{10}$.

O sistema de educação deve ser capaz de fortalecer a auto-estima e o estímulo a práticas de vida saudáveis, além de propiciar ambientes que reforcem a promoção da saúde e que apóiem projetos que integrem a escola e a comunidade ${ }^{6}$, e, nesse contexto, o educador tem um papel fundamental a desenvolver.

Campos $^{11}$ refere que o educador pode criar condições favoráveis para a ampliação do conhecimento dos alunos, incentivando-os a se tornarem aprendizes inquisitivos, criativos e críticos. O educador se revela como principal disseminador de conhecimentos e realizador de ações capazes de despertar o interesse e a participação de cada membro dessa comunidade. Kealey et al. ${ }^{12}$ afirmam que este profissional é a chave da efetividade na implantação de projetos e, em conseqüência disso, faz-se necessário o treinamento e o adequado preparo do mesmo. Entretanto, existem lacunas na formação desses profissionais, referentes a temas voltados à promoção de hábitos alimentares saudáveis. Portanto, são necessárias estratégias de capacitação dos mesmos, tornando-os aptos a serem disseminadores desses novos padrões e estilos de vida mais saudáveis.

Neste contexto, no projeto A Escola Promovendo Hábitos Alimentares Saudáveis, doravante chamado de Projeto, desde 2001 procura-se promover e inserir práticas alimentares saudáveis 
nas escolas de Educação Infantil e de Ensino Fundamental até a $4^{a}$ série, públicas e privadas do Distrito Federal, Brasil. Neste Projeto realizam-se, desde 2003, capacitações para educadores e donos de cantinas escolares, sendo o mesmo uma linha de pesquisa integrante do Observatório de Políticas de Segurança Alimentar e Nutrição da Universidade de Brasília'13.

O Eixo Capacitação de Educadores, umas das principais vertentes do Projeto, oferece bases técnico-pedagógicas e competências necessárias ao trabalho autônomo de educação nutricional na escola13,14. Possui caráter contínuo, com constante aperfeiçoamento da sua metodologia, garantindo a sustentabilidade das ações para as escolas participantes.

Neste artigo, apresenta-se de forma sistemática a construção metodológica do curso de educação nutricional para educadores de ensino infantil e fundamental até a $4^{a}$ série. Isto possibilitará um olhar mais aprofundado sobre as reais necessidades e as expectativas de formação destes atores sociais na temática de alimentação e nutrição, além de detalhar a trajetória e as estratégias metodológicas utilizadas neste percurso. Entende-se que a observação crítica dos passos necessários ao planejamento de uma capacitação dessa natureza, dentro do conhecimento técnico científico disponível, será de grande valia para iniciativas similares, em outras localidades.

\section{MÉ T O D O S}

Este trabalho foi realizado em quatro escolas de diferentes realidades socioeconômicas do DF, sendo uma pública urbana de Brasília, duas públicas rurais de Brazlândia e São Sebastião e uma privada urbana de Samambaia. Os critérios para esta seleção foram: interesse da escola; necessidade de desenvolvimento de ações nessa linha; receptividade da direção da escola; ser preferencialmente pública; e ter participação do dono da cantina da escola no Curso de Capacitação para Donos de Cantinas Escolares realizado pelo Projeto.
Todos os educadores foram convidados a participar das etapas do planejamento do Curso de educação permanente em alimentação e nutrição descritas a seguir, pois a aceitação e a apropriação da oficina pelo grupo são fundamentais para o sucesso da mesma ${ }^{15}$. Porém, a participação foi voluntária, sendo a expressão do desejo dos participantes respeitada.

A proposta de construção do curso de educação nutricional para educadores está inserida na concepção da educação permanente, e foi realizada em quatro etapas, segundo o método de intervenção psicossocial, descrito por Afonso ${ }^{15}$. Este é formado pelas etapas de: demanda; pré-análise; foco e enquadre; e planejamento flexível.

Na primeira etapa foi realizada a análise de demanda, processo pelo qual os indivíduos do grupo a serem capacitados foram reconhecidos. Esta fase envolve elementos sociais, culturais e subjetivos que precisam ser conhecidos em um dado grupo social. Para isso, realizaram-se encontros com os educadores e, nestes momentos, utilizou-se a metodologia da problematização baseada no Método do Arco de Charles Maguerez ${ }^{16}$. Este é constituído por cinco fases - observação da realidade, pontos chaves, teorização, hipóteses de solução e aplicação à prática. As duas primeiras fases foram realizadas na etapa demanda e as demais foram contempladas nas outras etapas de planejamento do Curso. Por meio deste método, pretendia-se que os educadores pudessem refletir sobre sua realidade, revelando assim, dificuldades, expectativas e temas fundamentais para a promoção de hábitos alimentares saudáveis em suas escolas. A partir disso, as informações coletadas foram agrupadas a alguns outros temas identificados pelo Projeto ao longo do tempo, ou mesmo referidos pela literatura científica, obtendo-se uma lista de temas.

Na etapa de pré-análise foi possível a definição dos temas a serem desenvolvidos no Curso, nas ações e nos encontros de acompanhamento, possibilitando a organização de acordo com seu conteúdo, obtendo-se assim os temas geradores. 
Além disso, este momento foi usado para responder à seguinte questão: Quais são as principais informações a serem discutidas?

Após a definição dos temas geradores partiu-se para a especificação do foco do planejamento, ou o tema geral do Curso. Ainda na terceira etapa, definiu-se o enquadre referente ao local e à duração de cada curso/atividade de acompanhamento. O enquadre deve facilitar a expressão livre dos participantes, a troca de experiências, a relação com o coordenador, a privacidade dos encontros e o espaço e o tempo necessários para fazer uma reflexão sobre o tema.

A última etapa consistiu no planejamento flexível, momento reservado para a definição dos objetivos do Curso e das ações de acompanhamento, detalhando-se previamente cada encontro e descrevendo-o em formato de planos de aulas. Cada tema gerador pode ser desenvolvido em um ou vários encontros, dependendo do número de encontros propostos e do interesse do grupo.

A teoria norteadora para o desenvolvimento das atividades do Curso foi a do construtivismo ${ }^{17}$, na qual se propõe a ampliação do conhecimento de forma ativa pelo sujeito, cujo foco é a construção do conhecimento pelo aluno e não a transmissão pelo professor. Nesse sentido, em cada atividade delineada observaram-se os ensinos construtivistas aplicados à realidade de cursos de capacitação. Para isto, utilizaram-se os aspectos fundamentais para um ensino crítico construtivista, citados por Jófili18, que são: considerar o conhecimento prévio do aluno; utilizar o moderador do Curso como auxiliador da construção do conhecimento de seus participantes e desenvolver estratégias de ensino que auxiliem os participantes a integrarem novas idéias aos seus conhecimentos prévios. Ainda, planejar o trabalho prático de forma a ajudar a construção do conhecimento por meio da experiência do mundo real e da interação social; possibilitar a reorganização de conhecimentos e sua análise crítica, e a identificação do participante como responsável pela sua própria aprendizagem.

As fases da metodologia de problematização que não foram contempladas na etapa de demanda (teorização, hipóteses de solução e aplicação à realidade) ${ }^{16}$, foram observadas no momento do planejamento, uma vez que o Curso deveria possibilitar condições para que os educadores desenvolvessem tais etapas durante sua execução.

Com o intuito de orientar a elaboração das atividades a serem desenvolvidas, e propiciar a avaliação das mesmas, foram traçados conhecimentos, habilidades e atitudes considerados essenciais para que os educadores possam ser agentes promotores da alimentação saudável na escola, por meio da inserção do tema Alimentação Saudável no currículo escolar. Estes itens foram construídos utilizando-se o conceito trazido por Deffune $\&$ Depresbiteris ${ }^{19}$, como sendo um conjunto amplo de diferentes saberes (saber-fazer, saber-ser, saber-agir). Espera-se que, ao final das ações de educação permanente, os educadores contemplem este conjunto de saberes.

O Projeto foi aprovado pelo Comitê de Ética em Pesquisa com Seres Humanos da Faculdade de Ciências da Saúde da Universidade de Brasília, conforme consta no processo 006/2005, atendendo a todas as exigências da legislação em questão.

\section{RES U LTA DOS}

Dos 59 educadores das escolas envolvidas neste estudo, $48(81,0 \%)$ participaram da etapa de demanda da construção do curso; e destes, 4 (8,5\%) eram de escola pública urbana, 17 (35,5\%) de escola pública rural e 27 (56,0\%) de escola particular urbana. As dificuldades e as expectativas resultantes desta etapa estão expressas no Quadro 1.

Os temas verificados na etapa pré-análise foram: alimentação saudável; opções de refeições saudáveis; estratégias para a promoção de hábitos alimentares saudáveis com a comunidade; contexto da alimentação na atualidade; aspectos legais referentes à alimentação no ambiente escolar e aproveitamento total de alimentos. 
Quadro 1. Dificuldades e expectativas de educadores. Distrito Federal, Brasil, 2006.

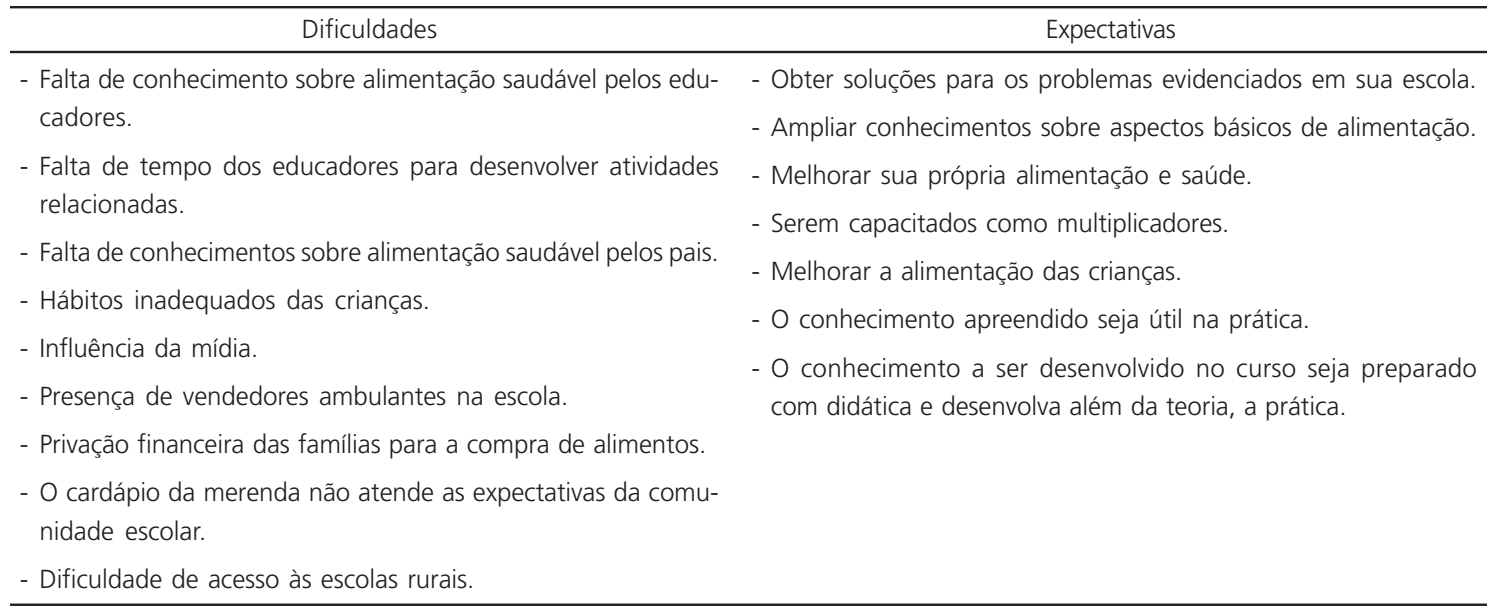

Quadro 2. Objetivos traçados para o curso e para as ações de acompanhamento com os educadores. Distrito Federal, Brasil, 2006.

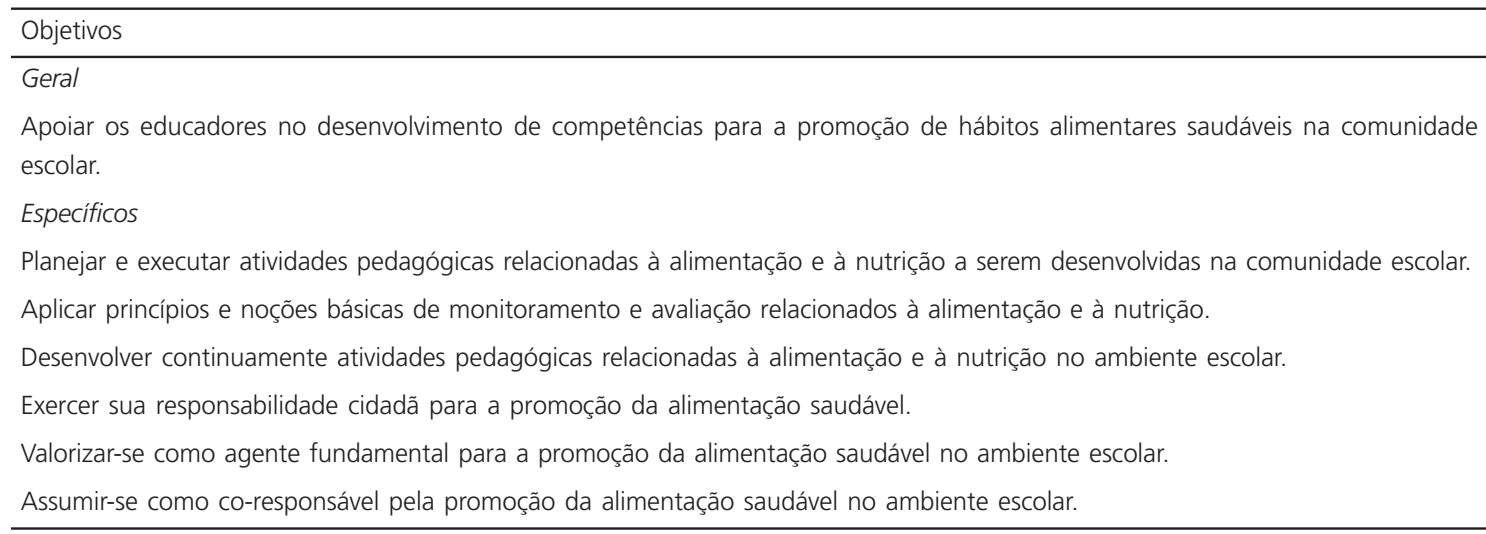

O foco do planejamento foi definido como Alimentação saudável na escola e o enquadre foi estruturado revelando as seguintes características: trata-se de um Curso de extensão certificado pela Escola de Extensão da Universidade de Brasília, com carga horária de 60 horas, sendo 21 horas presenciais, caracterizadas por três encontros a se realizarem na Universidade; e 39 horas de aplicação prática nas escolas onde atuam os educadores participantes.

Os objetivos do Curso e das ações de acompanhamento, desenvolvidos em conjunto com os educadores na etapa do planejamento flexível, estão descritos no Quadro 2 e indicam uma expectativa de ação que envolve, principalmente o apoio aos educadores para o desempenho adequado de suas competências.

Para as ações de educação nutricional a serem desenvolvidas com os educadores, foram traçadas cinco competências esperadas ao final das ações de educação permanente: planejamento, execução, monitoramento e avaliação de atividades pedagógicas relacionadas à alimentação e nutrição, desenvolvimento contínuo destas e exercício da responsabilidade cidadã para promoção da alimentação saudável.

Para o alcance da primeira competência, identificaram-se como necessários ao planejamento, os conhecimentos sobre metodologia de problematização da realidade, os processos 
participativos, as estratégias de sensibilização em nutrição e alimentação saudável, e as técnicas de planejamento. Esses conteúdos são importantes para identificar os problemas alimentares e nutricionais nas escolas e suas prioridades, além de estabelecer parcerias com outros membros da comunidade escolar. Ainda, para cada atividade planejada, foi necessário definir objetivos, construir e descrever a atividade conforme sua realidade e identificar os recursos necessários para a execução. As atitudes esperadas são: problematizar a realidade junto à comunidade escolar e planejar as atividades pedagógicas referentes à alimentação saudável de acordo com a realidade.

Os conhecimentos necessários para a segunda competência, referente à execução, são os de liderança docente, organização e alimentação/nutrição. Espera-se que os educadores organizem sua equipe, definam suas atividades, mobilizem os recursos necessários e desenvolvam as atividades conforme o planejado para cumprirem adequadamente o planejamento das atividades.

A terceira competência, relativa ao monitoramento e avaliação, exige dos educadores conhecimento sobre metodologia de avaliação, construção de indicadores avaliativos e comparação entre objetivos traçados e ações efetuadas. As habilidades consistem em estimular e apoiar a comunidade escolar na participação do processo avaliativo, e operar adaptações ao planejamento das ações de acordo com o resultado da avaliação. A atitude referente a essa competência é a execução das habilidades citadas.

A legislação básica da educação, os Parâmetros Curriculares Nacionais do Ministério da Educação e Cultura ${ }^{20}$, os conceitos e fundamentos de transversalidade, a metodologia de planejamento de ações, as técnicas de sensibilização e o construtivismo segundo Vygotsky ${ }^{18}$, são os conhecimentos estabelecidos para a quarta competência. Dentre as habilidades, foram identificadas como essenciais a compreensão do papel da escola como ambiente promotor da saúde e da alimentação saudável; a inserção do tema alimentação e nutrição no currículo escolar de forma transversal; e a sensibilização da comunidade para sua importância visando à implantação do processo.

Quanto à quinta competência, o exercício da responsabilidade cidadã para a promoção da alimentação saudável requer conhecimentos relativos à cidadania e aspectos básicos sobre temas sociais (alimentação, educação, saúde, lazer, entre outros), para promover no educador a compreensão de que o ambiente escolar é responsável pela multiplicação de atitudes positivas.

Após estas ações, os módulos do Curso foram estruturados agrupando-se temas geradores que pudessem ser desenvolvidos no mesmo contexto, a fim de possibilitar a melhor aplicação dos recursos físicos, humanos e do tempo. Estes módulos foram assim planejados: Aspectos básicos da alimentação saudável (20 horas); Alimentação saudável como tema transversal e interdisciplinar (8 horas); Formas práticas de desenvolver a alimentação saudável no currículo escolar (32 horas). Cada encontro foi estruturado em, pelo menos, 3 momentos básicos: um momento inicial de preparo do grupo para o trabalho do dia (dinâmicas de entrosamento, aquecimento, relaxamento), um intermediário, em que o grupo se envolve em atividades variadas que facilitem sua reflexão e elaboração do tema desenvolvido, e um de sistematização e avaliação do trabalho do dia, que permite aos participantes a visualização de sua produção como um grupo de trabalho.

\section{DIS CUSS Ã O}

A educação nutricional, disciplina obrigatória nos currículos de nutrição, apresenta certa fragilidade no seu ensino durante a graduação, principalmente devido à não contextualização dos problemas alimentares a partir de informações do campo das ciências humanas e sociais, o que tende a comprometer a qualidade e a eficiência dos programas que envolvem sua temática ${ }^{21}$. Além disso, verifica-se que o modelo tradicional da educação nutricional se concentra no saber técnico da 
nutrição e não utiliza técnicas e métodos de ensino problematizadores e construtivistas ${ }^{21}$, que poderiam formar indivíduos conscientes e críticos de suas responsabilidades como cidadãos. Entende-se que a eficiência de programas de promoção da alimentação saudável está relacionada com o envolvimento dos fatores sócio-ambientais do grupo abordado 22 .

De acordo com Meyer et al. ${ }^{23}$, os projetos educativos em saúde continuam sendo desenvolvidos na perspectiva da transmissão de um conhecimento especializado e não da sua construção. Esta construção coletiva precisa ser observada juntamente com as práticas relacionadas aos modos como cada cultura concebe o viver de forma saudável. Especificamente sobre a educação nutricional no contexto da promoção de práticas alimentares saudáveis, segundo Santos ${ }^{24}$, verifica-se que são escassas as reflexões sobre as possibilidades e os limites desta área do conhecimento da nutrição, assim como orientações para seu desenvolvimento metodológico de forma mais consistente.

No universo escolar, propostas dessa natureza devem ter como público a figura essencial do educador, para que assim se aumentem as possibilidades de sucesso no alcance dos objetivos, sendo que este deve estar capacitado nesta temática para poder desempenhar a contento esta tarefa. Nesse sentido, o método apresentado neste artigo, utilizado para a construção da educação permanente, sensibiliza e estimula seu beneficiário direto, o educador. Também são definidas as etapas metodológicas necessárias para o desenvolvimento de uma proposta problematizadora, construtivista, e capaz de possibilitar aos educadores, a construção de competências para a inserção do tema alimentação saudável de forma transversal e interdisciplinar no contexto da sala de aula. Traz, portanto, uma metodologia inovadora pautada na criação de espaços democráticos e participativos, com uso de métodos e técnicas de ensino construtivistas.

Sabe-se que o educador atua como ótimo instrumento multiplicador de informações para todos os âmbitos da escola. Sua capacitação e comprometimento geram desenvolvimento e crescimento da comunidade escolar, tendo como conseqüência o enriquecimento não apenas cognitivo, mas a melhora do desempenho e da participação dos estudantes sob o ponto de vista social dos membros da comunidade ${ }^{13}$.

Verificou-se que as principais dificuldades relatadas pelos educadores para o desenvolvimento de ações de promoção da alimentação saudável, identificadas na etapa de demanda, também foram citadas em outros estudos ${ }^{13,25}$. Nesse sentido, os educadores reconhecem claramente a inadequação dos hábitos alimentares das crianças. Esse cenário pode ser modificado a partir do desenvolvimento de estratégias educacionais de promoção da alimentação saudável no ambiente escolar e familiar. Porém, primeiramente, é necessário o apoderamento da comunidade para a tomada de atitudes eficazes frente aos problemas encontrados em cada realidade ${ }^{5}$. Por outro lado, o conhecimento inadequado ou insuficiente dos pais e dos educadores sobre alimentação saudável pode interferir na formação dos hábitos alimentares dos escolares.

Observa-se que o conhecimento dos educadores é a chave da efetividade dos projetos implantados nas escolas ${ }^{13}$. Dessa forma, a capacitação dos educadores é necessária para o sucesso na elaboração das atividades de alimentação e nutrição, uma vez que, tradicionalmente, a formação dos educadores brasileiros não contempla essa dimensão20,26.

Além disso, aliada ao conhecimento inadequado, a falta de tempo para desenvolver ações educativas em sala de aula, relatada pelos educadores, é uma das maiores barreiras a ser vencida nesta proposta educativa. A maioria acredita que para o desenvolvimento de ações de educação nutricional, se faz necessária a inclusão de uma nova disciplina. Por meio da abordagem interdisciplinar e transversal, pretende-se propiciar o trabalho de aspectos variados da alimentação de forma contínua, articulada com a prática diária dos educandos, ultrapassando as barreiras entre as disciplinas de forma didática e o cotidiano da 
escola. Isto possibilitará, ainda, o desenvolvimento desse tema com a mesma relevância das áreas convencionais do conhecimento ${ }^{20}$.

Um ponto relevante verificado no planejamento do Curso foi a diferença de realidades entre escolas rurais e urbanas. Como pôde ser visto, foram ouvidos indivíduos provenientes destes dois ambientes, sendo relatada a dificuldade de acesso às escolas rurais e a falta de recurso financeiro das famílias para a compra de alimentos, o que infringe o direito humano à alimentação adequada e a garantia da segurança alimentar e nutricional. Além disso, os educadores perceberam que a execução do cardápio do Programa de Alimentação Escolar no Distrito Federal não está em concordância com a cultura alimentar da região.

Nesse sentido, o método utilizado possibilitou a identificação de certas dificuldades, que redundaram na inserção de conteúdos específicos nos módulos de capacitação. Neste exemplo, estes temas foram agregados ao módulo referente aos princípios da alimentação saudável por meio da apresentação dos direitos e garantias acerca da alimentação, e da formulação de estratégias para solucionar as questões ao alcance dos educadores. Deve ser enfatizado que o estímulo e a articulação pelo educador da participação de diversos membros da comunidade escolar, durante as fases de planejamento e realização de ações educativas para saúde, são fundamentais para o alcance das atividades planejadas de acordo com as necessidades da comunidade. Destaca-se que isto se encontra previsto nas competências a serem atingidas.

Ressalta-se ainda que os problemas identificados pelos educadores, em sua maioria, foram problemas comuns a todas as escolas, e as soluções devem surgir do coletivo, por meio de diagnóstico preciso, de objetivos a serem alcançados, da discussão, da tomada de decisão, da execução e da avaliação das etapas desenvolvidas.

Na etapa de demanda, verificou-se que a expectativa de melhorar o conhecimento sobre alimentação e nutrição relatada pelos educadores é o primeiro passo para a promoção da saúde da população a curto, médio e longo prazos, no ambiente escolar. Contudo, para que o educador se transforme em agente promotor de hábitos alimentares saudáveis, é essencial que possua além do conhecimento dos preceitos teóricos de alimentação e nutrição - uma postura consciente da importância de sua atuação na formação dos hábitos alimentares da criança. Neste trabalho, o pressuposto é de que educadores competentes e motivados podem tornar-se agentes transformadores do comportamento alimentar de crianças.

A metodologia proposta por Afonso ${ }^{15}$ permitiu construir uma proposta de educação permanente a partir dos sujeitos psicossociais vinculados ao seu contexto cotidiano, sendo desenvolvida de acordo com as condições socioeconômicas da comunidade. Além disso, facilita a mobilização do grupo, pois os temas se relacionam com sua experiência, tocam nos conflitos e possibilidades e aguçam o desejo de participação e troca.

Para o Ministério da Saúde, a Educação Permanente é a aprendizagem no trabalho, em que o aprender e o ensinar se incorporam ao cotidiano das organizações e ao trabalho ${ }^{27}$. Fundamenta-se no diálogo entre o aprender e o ensinar mútuo, dando oportunidades de troca de experiências e discussões, envolvendo uma relação de cuidado e comprometimento com o processo e as pessoas ${ }^{28}$.

Além disso, entende-se que a educação permanente contempla os conceitos de diálogo, participação, ação-reflexão-ação (conscientização) e transformação ${ }^{29}$. Na concepção de Paulo Freire, ela engloba o diálogo e a comunicação, que geram críticas e problematização ${ }^{30}$. Nesse sentido, a proposta educativa apresentada não se encerra no Curso de Capacitação. Nela há uma abordagem que também envolve a educação permanente, tanto pelo fato de a escola ser um ambiente versátil, quanto pelas dificuldades de pôr em prática os conhecimentos construídos. Assim, ao longo das ações educativas, serão possíveis o acompanhamento e a identificação dos conhecimentos, habilidades e práticas construídos, assim como dos que necessitam ainda ser mais desenvolvidos para o alcance da competência em questão. 
Portanto, entende-se que a construção de uma proposta de educação nutricional baseada nestes princípios, e elaborada de forma sistemática, com base em conhecimentos e técnicas metodológicas estabelecidas, possibilitará o apoderamento dos indivíduos.

Para a avaliação das ações educativas propostas neste trabalho - de acordo com as tendências conceituais da inserção de atividades pedagógicas de alimentação saudável no currículo escolar - será necessário identificar e avaliar o número e a qualidade de atividades relacionadas à alimentação e nutrição desenvolvidas no currículo escolar, bem como a abrangência destas ações educativas (envolvimento com a comunidade escolar). Esta se constitui em outra etapa de ação a ser focalizada pelo projeto A Escola Promovendo Hábitos Alimentares Saudáveis.

\section{O N C L US Ã O}

As ações de promoção da alimentação saudável precisam ser pautadas em aspectos metodológicos consistentes para que possam alcançar seus objetivos. Dentre tais aspectos destacam-se a estratégia de construção das ações, em especial para a definição dos temas a serem abordados; e a proposta pedagógica a ser utilizada. Esta recomendação torna-se ainda mais essencial no contexto escolar, no qual os aspectos didáticos são fatores fundamentais para o alcance do público ao qual se destinam as ações, no caso, as crianças.

Diante das mudanças no perfil epidemiológico atual da população brasileira, assim como no seu padrão alimentar, com preocupantes reflexos já observados na população infantil, verifica-se a necessidade de colocar em prática medidas factíveis de promoção da alimentação saudável, destacando-se neste contexto, o espaço e o ambiente da escola.

Nesse sentido, a proposta apresentada aqui se traduz em uma opção norteadora para que ações de educação nutricional, que visem a contribuir para a alteração deste perfil epidemiológico, possam ser desenvolvidas. No entanto, em virtude das várias opções metodológicas existentes e dos distintos cenários educacionais encontrados, faz-se necessária a realização de outros estudos em que se apresentem e discutam o planejamento e o desenvolvimento de ações de educação nutricional no universo escolar.

Esta contribuição foi restrita ao público-alvo dos educadores e ao processo metodológico apresentado. Entende-se, no entanto, que outras possibilidades existem e devem ser estimuladas para que, cada vez mais programas eficientes sejam desenvolvidos para a promoção de hábitos alimentares saudáveis. Isto deve ser feito com os diversos atores do universo escolar, traduzindo-se, assim, em melhoria concreta das suas condições de saúde e nutrição.

\section{A GRADECIMENTOS}

Aos alunos de graduação e pós-graduação em nutrição participantes do projeto A Escola Promovendo Hábitos Alimentares Saudáveis, que são, sem dúvida, a sua alma.

\section{COLABORADORES}

R. BERNARDON, J.R.M. SILVA e G.T. CARDOSO participaram do planejamento, da execução da pesquisa, da elaboração do artigo e da versão final. R.A. MONTEIRO participou da elaboração do artigo e da aprovação da versão final. N.F.A. AMORIM contribuiu com o planejamento, a execução da pesquisa e a aprovação da versão final. B.A.S. SCHMITZ e M.L.C.F. RODRIGUES participaram da concepção, do planejamento, da orientação da pesquisa, da elaboração do artigo e da versão final.

\section{REFERÊ NCIAS}

1. Organização Pan-Americana da Saúde. Doenças crônico-degenerativas e obesidade: estratégia mundial sobre alimentação saudável, atividade física e saúde. Brasília: OPAS; 2003.

2. Escoda MSQ. Para a crítica da transição nutricional. Ciênc Saúde Coletiva. 2002; 7(2):219-26.

3. Filho $M B$, Rissin $A$. A transição nutricional no Brasil: tendências regionais e temporais. Cad Saúde Pública. 2003; 19(1):181-91. 
4. Wang $Y$, Monteiro C, Popkin BM. Trends of obesity and underweight in older children and adolescents in the United States, Brazil, China, and Russia. Am J Clin Nutr. 2002; 75(6):971-7.

5. Brasil. Ministério da Saúde. Secretaria de Vigilância Sanitária. Política nacional de promoção da saúde. Brasília: Ministério da Saúde; 2006.

6. Pelicioni MCFE, Torres AL. Promoção da saúde: a escola promotora da saúde. São Paulo: Faculdade de Saúde Pública da Universidade de São Paulo; 1999. Séries Monográficas.

7. Organización Panamericana de la Salud. Promoción y educación de la salud escolar, una perspectiva integral: marco conceptual y operativo. Washington (DC): OPAS; 1995.

8. Lefrève $F$, Lefrève $A M C$. Promoção de saúde: a negação da negação. Rio de Janeiro: Vieira \& Lent; 2004.

9. Organización Panamericana de la Salud. Educación para la salud: un enfoque integral. Washington (DC): OPAS; 1995. Série HSS/SILOS, n.37.

10. Gonçalves FD, Catrib AMF, Vieira NFC, Vieira LJES. Health promotion in primary school. Interface Comunic Saúde Educ. 2008; 12(24):181-92.

11. Campos MM. A formação de professores para crianças de 0 a 10 anos: modelos em debate. Educ Soc. 1999; 20(68):126-42.

12. Kealey KA, Peterson AV, Gaul MA, Dinh KT. Teacher training as a behavior change process: principles and results from a longitudinal study. Health Educ Behav. 2000; 27(1):64-81.

13. Schmitz BAS, Recine E, Cardoso GT, Silva JRM, Amorim NFA, Bernardon $\mathrm{R}$, et al. A escola promovendo hábitos alimentares saudáveis: uma proposta metodológica de capacitação para educadores e donos de cantina escolar. Cad Saúde Pública. 2008; 24(2):312-22.

14. Rodrigues MLCF, Silva JRM, Bernardon R, Amorim NFA, Fernandez PM, Monteiro RA, et al. A escola promovendo hábitos alimentares saudáveis: uma estratégia educacional para a promoção da alimentação saudável na rede de ensino infantil e fundamental. In: Freitas D, organizadora. Tecendo redes: conexão entre saberes para a educação. Rio de Janeiro: E-papers; 2007. v.1.

15. Afonso MLM. Oficinas em dinâmica de grupo: um método de intervenção psicossocial. Belo Horizonte: Edições do Campo Social; 2002.

16. Berbel NAN. A problematização e a aprendizagem baseada em problemas: diferentes termos ou diferentes caminhos? Interface Comunic Saúde Educ. 1998; 1(2):139-54.

17. Werneck VR. Sobre o processo de construção do conhecimento: o papel do ensino e da pesquisa. Ensaio Aval Pol Públ Educ. 2006; 14(51):173-96.
18. Jófili Z. Piaget, Vygotsky, Freire e a construção do conhecimento na escola. Educ Teor Prát. 2002; 2(2): 191-208.

19. Deffune D, Depresbiteris L. Competências, habilidades e currículos de educação profissional: crônicas e reflexos. 2a. ed. São Paulo: SENAC; 2002.

20. Brasil. Ministério da Educação. Parâmetros curriculares nacionais: introdução aos PCN. Brasília: Ministério da Educação; 1997.

21. Ferreira VA, Magalhães R. Nutrição e promoção da saúde: perspectivas atuais. Cad Saúde Pública. 2007; 23(7):1674-81.

22. Neumark-Sztainer D, Story M, Perry C, Casey MA. Factors influencing food choices of adolescents: findings from focus group discussions with adolescents. J Am Diet Assoc. 1999; 99(8):929-37.

23. Meyer DEE, Mello DF, Valadão MM, Ayres JRCM. "Você aprende. A gente ensina?" Interrogando relações entre educação e saúde desde a perspectiva da vulnerabilidade. Cad Saúde Pública. 2006; 22(6):1335-42.

24. Santos LAS. Educação alimentar e nutricional no contexto da promoção de práticas alimentares saudáveis. Rev Nutr. 2005; 18(5):681-92.

25. Hursti UK. Factors influencing children's food choice. Primary prevention of cardiovascular disease in childhood. Ann Med.1999; 31(1):26-32.

26. Mohr A, Schall VT. Rumos da educação em saúde no Brasil e sua relação com a educação ambiental. Cad Saúde Pública. 1992; 8(2):199-203.

27. Brasil. Ministério da Saúde. Departamento de Gestão da Educação na Saúde. Termo de referência da política nacional de educação permanente. [acesso 2008 ago 15]. Disponível em: <http:// portal.saude.gov.br/portal/arquivos/pdf/termo dereferencia23.pdf $>$.

28. Lopes SRS, Piovesan ETA, Melo LO, Pereira MF. Potencialidades da educação permanente para a transformação das práticas de saúde. Comun Ciênc Saúde. 2007; 18(2):147-55.

29. Espinoza LMM. A conscientização como fundamento da educação em saúde às pessoas hospitalizadas com tuberculose pulmonar [mestrado]. Florianópolis: Universidade Federal de Santa Catarina; 1998 [acesso 2008 jul 17]. Disponível em: <http://www.nfr.ufsc.br/pen/Brazil/mestrado/ 180.htm>.

30. Zacarias VLCF. Paulo Freire: biografia resumida: o caminho de um educador. [acesso 2008 ago 15]. Disponível em:<http://www.centrorefeducacional. com.br/paulo>.

Recebido em: 11/5/2007

Versão final reapresentada em: 2/3/2009 Aprovado em: 27/4/2009 